Dr. Dušana

Findeisen

Slovenska univerza za tretje življenjsko obdobje

\title{
O POVEZLJIVOSTI ELEMENTOV RAZLIČNIH NAČINOV UČENJA, METOD IN ZNANJA
}

POVZETEK

Avtorica uvodoma predstavi, kako različni teoretiki izobraževanja odraslih obravnavajo metode, nato pa proučuje vrednost in povezljivost posameznih elementov »učenja s poskusi in napakami« in »nedirektivnega učenja«. Tako kot so metode eklektične, razmišlja avtorica, so lahko eklektični tudi načini učenja. Avtorica ilustrira svojo hipotetično trditev z analizo »antimetode " francoskega režiserja Mauricea Pialata in jo kontrastira z metodo/metodami, kjer je zakoličen cilj in je zakoličena pot, kjer gre za vnaprej postavljen, v zaporedne sekvence urejen proces, kakršnega najpogosteje srečujemo pri snemanju filma po scenariju, režiranju gledališke predstave, vizobraževanju odraslih. Avtorica opozori na to, da je tudi učenje veščin (kako nekaj naredimo) povezano z učenjem o tem, »kako biti«, in nazadnje tudi, da metoda ne more služiti vsiljevanju znanja in resnice, saj se tako rušijo okoliščine, ki omogočajo pridobivanje ali ustvarjanje znanja.

Ključne besede: učenje s poskusi in napakami, nedirektivno učenje, metoda, izobraževanje odraslih, film

\section{ON COMBINING ELEMENTS OF DIFFERENT WAYS OF LEARNING, METHODS AND KNOWLEDGE - ABSTRACT}

The paper deals with different thinkers' attitude towards methods in adult education. It examines the value of some elements of »trial and error learning « and »non-directive learning «. Like a multifaceted approach based on elements drawn from different methods, the way we learn can also be eclectic. To illustrate this assertion, the author analyses the »anti method « used by Maurice Pialat, a French film director, contrasting it with methods in which the aim is set in advance and the process leading towards it is organised in sequences. This is most often the case in script-based shooting of films, directing a theatre performance or running adult education. Moreover, the author argues that learning about how to do something is combined with learning about how to be. She further emphasises that methods should not be used to impose one's knowledge and one's reality on the learner, thus destroying circumstances necessary for gaining or creating knowledge.

Keywords: trial and error learning, non-directive learning, method, adult education, film

UDK: 374.7

DOI: http://dx.doi.org/10.4312/as.19.4.90-95

\section{UVOD}

Načini učenja in metode. Konceptualiziramo jih, spravljamo v strogo ločene »škatlice«, jih opremimo z nalepkami, kjer jasno piše, za kateri način učenja ali metodo gre. A zdi se, da sredi življenja, sredi prakse izobraževanja odraslih, tako jasna razmejitev ni mogoča. Se različni načini učenja in metode prepletejo? Kako z načini učenja, metodami in učnimi strategijami do znanja in do kakšnega znanja? To so bistvena vprašanja, ki jih odpiram v tem prispevku.

\section{O METODAH IN NAČINIH UČENJA V IZOBRAŽEVANJU ODRASLIH}

Nicolas de Condorcet v svojem razmišljanju o učenju slavi metodo. »Več kot je luči in 
spoznanj, popolnejše so metode poučevanja [...] Mladenič, ki zapušča našo šolo, ima več pravega znanja, kot ga je lahko prinesel dolgotrajni trud velikih duhov [...] Čedalje dalekosežnejše metode poučevanja, ki si sledijo druga za drugo, v kratkem času združijo vse resnice, ki so jih genialni duhovi razglabljali celo stoletje.«(Condorcet v Findeisen, 1995: 34)

Ameriški teoretik Eduard Lindeman tako zelo slavi metodo v izobraževanju odraslih, da se mu zdi, da je vse metoda, vsebina izobraževanja pa pravzaprav ni pomembna. Izobraževanje odraslih naj razvije kritično in analitično mišljenje in delovanje. »Izobraževanje je metoda, « zapiše, kajti »situacijam da okvir in omogoči analizo in razdelitev kompleksne celote na obvladljive, razumljive dele. Je pa tudi metoda, ki nakaže smer delovanja.«(Lindeman, 1926: 115)

John Holt (1964) verjame, da je pomembno, da znanje pridobivamo in ga začenjamo tudi takoj uporabljati; gre za učenje z delovanjem. Ne gre namreč, da bi se najprej učili igrati violino in bi jo šele nato igrali. Učenje je že igranje violine. To krepi želje, prizadevanja, hotenja, navdušenje za učenje, skratka motivacijo.

Učenje s poskusi in napakami ali »učenje $\mathrm{z}$ uspehom«. Thorndike ga je leta 1931 konceptualiziral pod imenom »zakonitost učinka« (Thorndike v: Delay, Pichot, 1969: 166). Utemeljeno je na načelu stimulusa in odziva ter podkrepitve. Ta način učenja naj bi uporabljali le, kadar drugih ne moremo ali ne znamo, saj je zamuden in obsega vrsto nepotrebnih korakov in kretenj. Človek, ki se uči, se giblje kot v nekakšnem tunelu, kjer nima pogleda na celoto, kjer nima pregleda, zato poskuša in dela napake. Celota se tako po tej poti šele oblikuje.

Drugim spet se zdi, da je pomembno, da odrasle učence izpostavimo vplivu virov, da učencem priskrbimo vire, da jih lahko uporabijo, da sami usmerjajo svoje učenje. Izobraževalci odraslih pa ustvarimo okolje za učenje nemalokrat tudi $\mathrm{z}$ uvodnim provokativnim nastopom. Rogers (1969) trdi, da obstajajo načini, kako biti z drugimi, načini, ki spodbujajo odkrivanje in srečevanje. Razmišlja o nedirektivnem učenju, v katerega učitelj ne posega in ga ne interpretira.

Omenjene metode in načini učenja so vsak zase možen odgovor na vprašanje, ki ga postavlja Aristotel: »S kovanjem postanemo kovači, a kako kovati, dokler nismo kovači?« Kako priti do cilja učenja? Domala sleherni način učenja, vsekakor pa sleherna metoda ima cilj, a pot do cilja je vsakokrat različna. $S$ prikazom metode dela - nekateri jo imenujemo kar antimetoda - francoskega režiserja Pialata zgolj hipotetično opozarjam na to, da je sredi življenja, v praksi, razmejitev med posameznimi načini učenja in metodami težko izvedljiva in da se posamezne značilnosti različnih načinov učenja in metod med seboj povežejo in kvalitativno vplivajo druga na drugo ter na končni rezultat učenja.

\section{NEDIREKTIVNO UČENJE TER NAČIN UČENIA S POKUSI IN NAPAKAMI}

»Antimetoda« režiserja Pialata ima številne značilnosti nedirektivnega učenja vseh udeleženih. Igralci vedo, da morajo ustvariti film, a pri tem so svobodni in lahko uberejo poti, ki se nakažejo v medsebojni interakciji. Pailat je v ozadju, kajti ve, kaj naj bi bil končni rezultat, kako doseči celoto, film. V Pialatovem primeru bi težko govorili o metodi dela, kajti ne gre za proces, urejen $\mathrm{v}$ zaporedne sekvence z jasno določenimi etapnimi cilji. Jasen je le končni cilj, izdelati edinstven film, a pot do tja ni jasna, ni zakoličena in, kot smo dejali, 
proces nima zaporednih sekvenc. Tako zelo je odprta za tisto, kar rodi, pri tem je omogočena in spodbujena interakcija vseh udeleženih. Vendar to ne pomeni, da Pialat nima slike tudi o procesu samem. Ima zelo široko sliko, a dovoli, da vanjo vstopijo vsi udeleženi in vsak na svoj način. Podobno tudi izobraževalci odraslih. Tudi oni imajo pred seboj jasen cilj, denimo navdušiti udeležence, omogočiti jim razumevanje težav $\mathrm{v}$ družini, poiskati nove trženjske prijeme, izdelati projekt ipd. Kako do tam, po kakšnih poteh, pa ni več le njihova skrb. Je skrb vseh.

V Pialatovem scenariju zmeraj vidimo prečrtane stavke, številne spremembe, a nazadnje vsakokrat nastane film, ki ni podoben nobenemu drugemu. Pialat je $v$ posebnem razmerju s pisano besedo in tako zanj tudi film ni v povezavi s pisano besedo, bolj s slikarstvom in glasbo. Scenarij zanj ni nujna etapa v ustvarjanju filma in Pialat zavrača scenaristično konstrukcijo, tako kot $\mathrm{v}$ načinu nedirektivnega učenja izobraževalec odraslih zavrne, da bi zakoličil metode, učne strategije, intervencije vseh vrst.

Pialatu ni všeč deskripcija prostorov v scenariju. Želi le dialog, nič dolgoveznih psiholoških opisov. Ne želi dobro napisanega scenarija. Življenje mora pljuskati ob ustvarjalce, treba je postaviti le cilj. Še več, film je zanj večna kriza (gr. krisis), estetska, življenjska, večno premoščanje sredi negotovega procesa, a vendarle procesa, ki vodi k cilju. Pialat uporablja antimetodo, bi lahko rekli. Vendar Pailatov način vključuje elemente načina učenja s poskusi in napakami in načina nedirektivnega učenja (naj ga imenujem tako!). Njegov način dela ima elemente metode: ima končni cilj, ima proces, četudi le delno določen in podvržen nenehnemu preoblikovanju na temelju interakcije, nima pa procesa, urejenega $v$ logičen niz zaporednih sekvenc z vnaprej določenimi etapnimi cilji.
Pialat je naredil veliko, okrog 40 projektov. Večino so zavrnili. Velikokrat je poskušal in prav res ni hodil po »kraljevi poti«. Vzel si je čas, da se izrazi, in ni hotel delati sam. Potreboval je odzive - značilnost nedirektivnega učenja. Pialat tudi ni pripovedoval, zanj bi že linerarno urejena pripoved bila nekaj, kar bi zaprlo nastajanje filma $v$ negibljivost. V njegovih filmih je veliko tišine, sredi katere se marsikaj odvije nepričakovano, pri čemer je Pialat igralcem dal najmanjše možno število navodil in so v njegovih filmih morali igralci sami, $\mathrm{v}$ interakciji $\mathrm{v}$ timu in z delovanjem, odkriti, kaj bo dalo sceni pomen (nedirektivno učenje).

Pialat je dal prostor, ni bilo kompozicije znotraj filmskega plana. Čutiti je bilo, da ve, kaj želi, a ne želi povedati, kar je znova značilnost nedirektivnega učenja, kjer učitelj ne posega $\mathrm{v}$ proces. »Moram pa narediti tako, da boš stvari naredil po svoje, « je govoril sodelavcem. Sodelavce je učil »nasilja celote«, ki se mora oblikovati z iskanjem. Delal je z več montažerji hkrati. Želel je, da ga scene presenetijo. Želel je ustvariti napetost, takšno, ki vodi proti cilju. Talente svojih sodelavcev in svoje lastne je osvobodil navodil, kar je značilnost nedirektivnega učenja. »Življenje ni homogeno, zato naj ne bo homogen niti produkt iskanja, «je govoril (Toubiana, 2013).

V njegovem ustvarjanju je bilo veliko poskusov, veliko napak. Ohranil je tisto, kar se mu je zdelo dobro, kar je bilo uspešno, in opustil tisto, kar ni bilo dobro (značilnost učenja s poskusi in napakami), kar ni podpiralo cilja, ki ga je želel doseči, in ni podpiralo nastajajoče celote filma. Če se učimo s poskušanjem in delanjem napak, poskušamo in delamo napake, opravimo kopico nepotrebnih korakov in kretenj ter začenjamo zmeraj znova, dokler zadnji poskus ni nazadnje pravi in tedaj opustimo vse predhodne. 
Pialatova antimetoda je zelo drugačna od metod, ki so urejene $\mathrm{v}$ proces $\mathrm{z}$ jasnimi, predvidenimi, zaporednimi sekvencami ter končnimi cilji. Nedirektivno učenje ter učenje s poskusi in napakami se pri njem prepleteta in sprašujem se, ali je učenje s poskusi in napakami nujno le tisto, ki ga $\mathrm{v}$ vedenjski psihologiji opredeljujejo kot učenje na temelju stimulusa in odziva ter podkrepitve. Je to res zmeraj najnižja vrsta učenja, kjer ni pregleda nad celoto?

\section{ZNAČILNOSTI, PREDNOSTI IN POMANJKLJIVOSTI METODE/ METOD V IZOBRAŽEVANJU ODRASLIH}

V izobraževanju odraslih si $\mathrm{z}$ metodo/metodami/učnimi strategijami prihranimo čas. Smo mirnejši, naredimo več. Naredimo manj napak in tveganje je manjše. Še posebej so metode in učne strategije dobrodošle pri učenju spretnosti in seveda še bolj pri učenju kompleksnih spretnosti, kot je denimo tuj jezik. Učenje razdelimo na zaporedne sekvence. Nobene ne smemo preskočiti, za sleherno intervencijo vemo, kdaj jo moramo izvesti, da pridemo, nazadnje, do rezultata. Brez metod se, denimo, učenci tujega jezika zgubijo in lahko se nalezejo napak, ki jih je izjemno težko izkoreniniti. Brez metode in učnih strategij si ne moremo zamisliti učenja klasičnih mrtvih jezikov, denimo učenja latinskega jezika.

Če bi se kovaški vajenec takoj lotil kovanja, bi bil $\mathrm{v}$ veliki nevarnosti, kakor tudi plavalec začetnik, če bi šel takoj v globoko vodo. Seveda pa lahko ugotovimo, da nekateri navidez, a le navidez, storijo prav to. Se vržejo v vodo in splavajo. Sedejo na kolo in se odpeljejo. Pa so v veliki nevarnosti? Večina da, a drugi, dislektiki na primer, se stvari naučijo navidez brez pripra- ve, brez preizkušanja, brez tipanja, brez metode. Pa vendar tudi pri njih ni tako, le da priprava poteka drugače, tako, da dolgo opazujejo, kako nekdo na primer sede na kolo, kako lovi in ulovi ravnotežje. To traja dlje časa, a nenadoma sedejo nanj tudi sami in se odpeljejo, kot da bi to počeli že leta dolgo, kot da bi bili vožnje vajeni že ves čas. Tudi v njihovem učenju je mogoče prepoznati zakonitosti metode, sistematičen red in zaporedje.

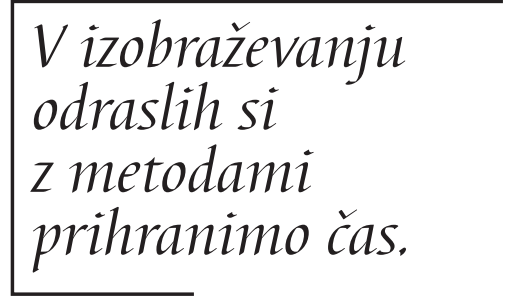

In vendar v današnjih časih družbene transformacije obstaja nasprotovanje metodi. Učenje naj bi potekalo spontano, ustvarjalno, brez metode, kajti metoda naj bi zmeraj pomenila avtoritarni poseg učitelja $\mathrm{v}$ učenje učenca. Metoda naj bi bila znamenje nasilja nad učencem. Metoda naj bi bila izraz volje drugega, postavila naj bi model, ki naj bi ga učenec uporabil, ponujala naj bi razdelitev dejavnosti $\mathrm{v}$ posamezna delna dejanja, ki se kasneje uverižijo v delovanje, proces, ki ga laho nadziramo. Tako bi človeško telo z uporabo metode postalo neke vrste robot, na voljo volji drugega ali drugih, robot, ki ga lahko sestavimo ali razstavimo po lastni želji. Če metodo vidimo na ta način, pač ne moremo reči, da je vredna več kot najpreprostejše učenje s poskušanjem in napakami in brez razmisleka. V tem primeru je metoda le oblika dresiranja.

\section{ZNANJE O TEM, KAKO SE KAJ NAREDI, IN ZNANJE O TEM, KAKO BITI}

Cilj, ki ga dosežemo s posameznimi načini učenja, metodami in učnimi strategijami, je lahko znanje, osebnostna rast (znanje, spretnosti, osebnostne lastnosti, stališča) ali kaj drugega. 
V sodobni družbi smo čedalje bolj specializirani, vsepovsod je tako, ne le v industriji, tudi $\mathrm{v}$ glasbi, športu ter celo $\mathrm{v}$ znanosti in medicini. Današnje težnje, da bi celo univerzitetni študij podredili gospodarstvu, pa po drugi strani omogočajo izobraževalcem vsaj to, da bolje zaznajo razliko med humanističnim izobraževanjem, ki služi človeku in njegovi osebnostni rasti, in tehničnim izobraževanjem, ki je v korist družbe. Humanistično izobraževanje je takšno, da omogoči pridobivanje veliko drugega znanja, ki vzgoji celo bitje. Humanistično izobraževanje je izobraževanje, kjer se učimo biti.

Dejstvo, da smo znanje o tem, kako se kaj naredi, pridobivali in pridobili, nam lahko pomaga, da pridobimo še drugo podobno. Znanje preprostih veščin je tako prenosljivo iz ene situacije v drugo. Če smo se naučili, denimo, da moramo pri pripravi pire krompirja maslo razstopiti v topli vodi, bomo to morebiti storili tudi pri pripravi riža ali polente. Vendar to velja le za preproste veščine in za preproste kompetence, ki se jih je mogoče naučiti. Sicer pa, ali se je sploh mogoče »naučiti« kompetenc? »Lahko se naučimo zakonov, vendar ali se lahko naučimo, kako narediti, da bo sodba pravična?« (Reboul, 2010: 195)

Otrok se mora naučiti vsega, naučiti se mora veščin. Mora se naučiti, kako nekaj vzeti, zgrabiti, pokazati in vse drugo. Sleherno znanje o tem, kako se nekaj naredi, mu omogoči, da odkrije metode, ki jim bo sledil v drugih okoliščinah, odkrije načine, kako se učiti, in obenem ustvarja sebe. Uči se, kako se spreminjati.

Otrok torej ob učenju veščin spozna tudi, kako se je mogoče učiti. Ustvarja znanje in ob tem ustvarja samega sebe. To dejstvo odkrijemo tudi pri odraslih in starejših odraslih ter njihovem znanju o tem, kako se kaj naredi. Pri pridobivanju tovrstnega znanja zme- raj pridobijo še marsikaj drugega in to drugo je bistveno. Gre namreč za izobraževanje in vzgojo celotnega bitja. V ilustracijo navajam borilne veščine, denimo karate. Kmalu odkrijemo, da ne gre za ta ali oni prijem, gre za vzgojo bitja, gre za tisto prenosljivo znanje, ki ga bo mogoče občutiti v vseh drugih okoliščinah. Kdor se uči karate, ve, da lahko borilne prijeme uporabi le, če ga napadejo, nikoli drugače. Pridobi obče veljavno spoznanje, da se sme boriti, ne pa tudi izražati agresivnosti. Uči se torej duhovne moči in pravi cilj tistega, ki se uči karate, ni karate, pravi cilj je on, je človek sam. $Z$ obvladovanjem tehnike pridobimo obvladovanje samega sebe - veščinsko znanje ali znanje o tem, kako se kaj naredi, se takrat spremini v znanje o tem, kako biti. Kvaliteta znanja o tem, kako se kaj naredi, je odvisna od tega, kako smo ga pridobili. (Reboul, 2010: 43).

Če je cilj učenja (angl. learning training), da se učenci nečesa naučijo, ta cilj ne dovoljuje, da bi tisti, ki ve in zna, svoje znanje vsilil drugim, pa naj bo to znanje še tako resnično in vredno. Vsiljevanje znanja namreč nasprotuje učenju: če znanje vsiljujemo, učencu rušimo okoliščine, ki mu omogočajo pridobivanje in ustvarjanje znanja, kot so: dvom, kritični dia$\log$, intelektualna poštenost, oporekanje.

Tudi učitelj, ki iz svojega znanja naredi izražanje moči in oblasti, s tem ruši okoliščine, ki ustvarjajo znanje. Če nekdo misli, da je tisto, kar pravi, resnično le zato, ker je tako zmeraj trdil in ker je trditev izrazil, tedaj se mu duh zapre in se zapre pred resnico. Takšen mentor pravzaprav nima znanja, boji se vprašanj in razmišljanja. Avtoritarnost ni znamenje znanja, marveč pomanjkljivega znanja in zaskrbljenosti. Res ni mogoče biti prepričevalen in hkrati doseči zmago nad drugimi. Resnica se tedaj spremeni $\mathrm{v}$ dogmo in mislec $\mathrm{v}$ tistega, ki misli nadzoruje in ocenjuje. 


\section{SKLEPNA BESEDA}

Učenje s poskusi in napakami je najnižja vrsta učenja, tako je zapisano v strokovni literaturi. Zamudna je in prinaša zmote, a prinese tudi uspešno znanje, ki ga ohranimo, vzdržujemo in uporabimo pri prihodnjih poskusih. Pri učenju s poskusi in napakami ni pregleda nad celoto, in tako Pialat uporabi zgolj nekatere elemente tega načina učenja. Če ta način učenja povežemo $\mathrm{z}$ elementi nedirektivnega učenja, lahko dosežemo tudi neslutene, edinstvene, nove rezultate. Navadno velja, da so metode zaradi zaporedja sekvenc varne in učinkovite, a če jih (izobraževalci, filmski ali gledališki režiserji) tistim, ki se učijo, vsilimo, gre za navadno dresuro. Metoda ne sme biti sredstvo, s katerim, spreminjajoč resnico v dogmo, izražamo svojo lažno moč nad njimi. Vsiljevanje namreč nasprotuje učenju, saj ruši okoliščine, ki omogočajo pridobivanje in ustvarjanje znanja.

\section{LITERATURA IN VIRI:}

Aristotel (2004). Ethique de Nicomaque. Paris: Garnier Flammarion.

Findeisen, D. (1995). Condorcetov prispevek k razmišljanju o vlogi učenja v človekovem in družbenem življenju. Andragoška spoznanja, 1, 3-4: 34.

Delay, J.; Pichot, F. (1969). Abrégé de psychologie. Paris: Masson \& Cle.

Holt, J. (1964). How children fail. New York: Pitman Publishing Company.

Hull, C. L. (1930). Simple trial and error learning: A study in psychological theory.

Psychological Review, 37, 3: 241-256.

Jarvis, P. (1990). International Dictionnary Of Adult And Continuing Education. London: Routledge.

Lindeman, E.(1926). The Meaning of Adult Education. New York: New Republic.
Moss, F. A. (ur.) (1934). Comparative psychology.

New York: Prentice-Hall.

Reboul, O. (2010). Qu'est-ce qu'apprendre. Paris:

PUF.

Rogers, C. (1969) Freedom to Learn. New York: Merrill.

Toubiana, S. (2013). La »méthode« Pialat. Dostopno na: http://www.canal-u.tv/video/cinematheque_ francaise/la_ldq uo_methode_pialat_par_serge_toubiana.11531 (23.2.2013) 